\title{
National Referral Center for Science and Technology
}

\author{
BY JOHN F. STEARNS
}

Semantics plagues us all. It is understandable that this should be the case when an information center sets out to define the terms on which successful mechanized retrieval depends. That this should be the case also when trying to draw the line between a "reference" service and a "referral" function is less to be expected. Yet the distinction that marks these two concepts has often been a problem for the National Referral Center in conveying an understanding of the role it is playing among the many organizations and institutions which today are striving to bridge the gap between producers and users of scientific and technical information.

The National Referral Center for Science and Technology was conceived as a central point at which data would be gathered, not on scientific and technical subjects, but on the extremely varied and increasingly numerous activities which, in some form, accumulate, process, and disseminate scientific and technical information. Using these data the center wouldas it is already doing-help those in need of information by putting them in touch with those who can provide it. This role of intermediary deserves emphasis. The center does not acquire scientific or technical literature, it does not index articles, nor does it process reports. It does not respond directly to technical questions, it does not prepare bibliographies, nor does it retrieve evaluated data. It does help strengthen and straighten the pipelines carrying today's heavy information flow by functioning as a "switching mechanism" within the complex scientific and technical community.
Mr. Stearns is Chief of the National Referral Center . . . which is in the Library of Congress.

Established in the Library of Congress with the support of the National Science Foundation, the center was given three basic tasks:/to identify all significant information resources in all fields of science and technology, including the social sciences, and to "catalog" them in the greatest possible detail in terms of scope, characteristics, and capabilities; to-insure full utilization of these resources by suggesting to inquiring organizations or individuals where their needs for specific materials can best be met and by publishing directories and listings of information resources in selected fields; 3nd to examine, on the basis of actual operating experience, the interrelationships within the nation's scientific and technical information network.

In clarifying the first task and in describing just what it means by an information resource, the center has again run into semantic obstacles. Most of us think of sources of information in the bibliographic sense of a specific journal or a particular report, and we wish to find the title and page which provide the immediate solution to our problem. The center is concerned with sources of information in this generally understood sense only insofar as it informs someone in search of a particular document where appropriate document collections are located. The term "resource" was chosen to indicate not books or pages, but places and people.

Special libraries, whether within the 
academic, industrial, or government framework, rank high among the resources with which the center hopes to establish continuing cooperation. Data and document centers, and indexing and abstracting services are also important information resources. The Center's interests extend, however, to the many capabilities which are built in to meet special needs of a particular organization, but which are in many cases known only to those within the organization. An information resource may consist of the background knowledge accumulated in connection with research performed by a government or private laboratory. It may consist of a collection of botanical specimens typical of a particular geographic area, of specialized studies made in support of the work of an agricultural experiment station, or of consulting services provided by a professional society through its members.

During the past several months the Center has asked thousands of universities, professional societies, trade associations, government agencies, and private industrial firms just what kinds of resources exist and has attempted to establish a register on which to draw for its referral services. The question posed is in essence: "What do you do?" The details needed in answer to this question, however, go far beyond general statements on subject specialization, size of collections, or reference or consulting services which are available. A physics library, for example, may be particularly strong in a narrow area of the field. It may include holdings that are valuable because they provide complete coverage of the literature for a particular time period, or because they include foreign materials. The center must know where such strengths lie, years of coverage, and the languages represented. A professional engineering society may announce that it provides reference and consulting services. Since few agree on what is to be assumed under this general statement, the center attempts to establish whether reference service includes answers to technical questions and bibliographic assistance, the extent of such assistance, and whether consulting services are provided by the staff of the society or through referral to society members. Of particular importance to the center are the conditions or restrictions which govern the use of a particular resource. Much of the wealth of scientific and technical information accumulated by private research groups is, for many reasons, not available to "outsiders." The center wants to find out what part is available and to what extent it is available. Similarly, government-sponsored activities are often described as accessible only to "qualified persons." The center wishes to know the qualifications needed. For the small, specialized library, limited staff and time are often a matter of concern which the center must take into account in making referrals.

All these considerations are essential not only in order that a requester may be referred to the resource most appropriate to his specific need but also to avoid referral to a resource which restricts its services to special users.

Although constant additional "input" will be necessary for a long time to come if the center is to consider itself truly knowledgeable with regard to the tens of thousands of resources which serve to meet the demands of today's science and technology, it tackled its second stated task by initiating referral services last spring. Relying on the records already accumulated on a few thousand resources and on the skill of an experienced referral staff, the center has during these brief months handled requests which are about to pass the one-thousand mark. Both spontaneous comments and solicited feedback from those who have received referral assistance have indicated that the "road sign" which the center represents is welcomed by many who are trying to 
choose paths in finding the address they are looking for.

The inquiries received to date cover an interestingly broad spectrum. They have dealt with such subjects as radiation shielding; heat transfer in relation to rocket nozzles and thrust chambers; corrosion resistance of galvanized steel; application of cryogenic materials to the freezing of food products; cause and effect of the deterioration of paper; care of laboratory animals; human problems posed by automation; fiber optics; solution mining; germicidal agents in use with air conditioning; cooling systems for ruby lasers; ultrasonic techniques for cardiovascular monitoring; methods of cutting living bone tissue; behavior of marine animals during solar eclipses; sea farming; geomorphological data confirming or rejecting the hypothesis of an expanding earth; national resources for brain research; and structural design requirements for the housing of elephants. These requests have come from individuals, educational institutions, government agencies, professional and other nonprofit organizations, and private industry. How such requests are handled may best be illustrated by specific examples.

The information specialist of a refining company who wished to locate sources of information on solution mining was referred to the Northern Ohio Geological Society, the United States Patent Office, the Michigan College of Mining and Technology, the Colorado School of Mines, and to a private company. In addition, the Engineering Societies library was suggested as a more general resource.

To the records management director of another company concerned with the cause and effect of the deterioration of paper, the center suggested that he contact the Office of Records Management at the National Archives, the Virginia State library, the Prevention of Deterioration Center, and the Technical Association of the Pulp and Paper Industry.
The graduate student who wrote to the center for information on methods of cutting living bone tissue was referred to the National Library of Medicine, the Science Information Exchange, the Brooke Army Medical Center in Texas, and the Army Medical Equipment Development Laboratory in New York State.

In these cases, as in all others, a brief description is given of the kinds of data, material, and services provided by each resource cited to indicate to the inquirer the nature of the assistance he may expect. The more background the center is given in terms of sources which someone in search of information may already have tapped and the purpose the requested data is to serve, the more effective the center can be in pinpointing the most suitable resource and in opening channels of exploration, thereby achieving its formally stated goal of "insuring the full utilization of existing resources."

There is a two-way-street aspect of the center's function which deserves particular emphasis and which bears discussion as it relates to college and research libraries. The center is vitally interested in obtaining information on the activities of such libraries and hopes that they will list their capabilities with the center. Equally important is what the center can do for the librarian. Referral functions are an integral part of any effective library, but in many instances workload and other considerations may limit the extent of such services. The National Referral Center provides a point of recourse to which the librarian may turn or to which he may direct his clients. The twoway street implies that the center wishes to insure use of local resources by knowing where they are and what they can do and at the same time provide support for these resources in cases where satisfaction of a request presents a problem. Limited operational experience has already indicated that many persons are not aware of the library facilities that are available 
in their immediate area. The center wishes to create this awareness and encourages inquirers to turn first to the resources that are geographically most convenient to them.

The center also hopes to assist libraries through its publications program which is now being developed. Directories describing information services in various subject fields will be issued and regularly updated, providing ready tools for librarians in handling questions requiring referral. Announcement will be made when these directories become available. Under consideration, also, is a system of cataloging for eventual mechanized retrieval of the data which are being gathered. This system must cover not only subject specialization, but language input and output, type of services, operational limitations, organizational affiliations, sponsorship, and administrative statistics. Those who have dealt with the problem of cataloging books, journals, and reports are in a particularly good position to understand that this is a task which will require both ingenuity and time.

Its third function, "examining the interrelationships within the nation's scientific and technical information network," the center will be able to approach only when its knowledge is sufficient for ready retrieval of all significant information resources in a given field and when the inquiries received by the center have reached statistically meaningful numbers. Such analysis will in effect be a balancing of the books, showing whether existing resources are adequate to meet information needs as reflected by those who have turned to the center for assistance.

Looking farther into the future, the National Referral Center also foresees exploration of information resources abroad. The letters of general inquiry which have come from information centers in foreign countries show that the information problem is a universal one. The center hopes that it will eventually be in a position to serve as a linkage not only within the national but also within the international information network.

\section{More about Statistics}

THE FOlLowing LeTter has been received by the President of ACRL in answer to a letter sent to the U.S. Commissioner of Education by George M. Bailey, executive secretary of ACRL at the request of the ACRL Board of Directors, and published in $C R L$ in March (page 110).

I want you and the members of your Association to know I appreciate the many letters received during the past month commending the Office of Education and specifically the Library Services Branch on the publication of "Library Statistics of Colleges and Universities, 1962-63."

You may be sure that we shall continue to work to improve both the quality and quantity of the returns, the speed of publication, and the analysis of the results. We value your efforts to help and encourage us.

Francis Keppel, U.S. Commissioner of Education

NoTE: Supplementary statistics for approximately 20 per cent of college and university libraries will be published this year for 1962-63 by the Library Administration Division of ALA. They will be available, at cost, for distribution at the LAD booth during the St. Louis Conference. 